\title{
Schwann Cell Surfaces but Not Extracellular Matrix Organized by Schwann Cells Support Neurite Outgrowth from Embryonic Rat Retina
}

\author{
N. Kleitman, P. Wood, M. I. Johnson, ${ }^{\dagger}$ and R. P. Bunge \\ Department of Anatomy and Neurobiology, and 'Departments of Pediatrics and Neurology, Washington University School \\ of Medicine, St. Louis, Missouri 63110
}

Despite evidence that glial cell surfaces and components of the extracellular matrix (ECM) support neurite outgrowth in many culture systems, the relative contributions of these factors have rarely been compared directly. Specifically, it remains to be determined which components of peripheral nerve support growth of central nerve fibers. We have directly compared neurite outgrowth from embryonic day 15 rat retinal explants placed onto beds of (1) Schwann cells without ECM, (2) Schwann cells expressing ECM (including a basal lamina), (3) cell-free ECM prepared from neuronSchwann cell cultures, (4) nonglial cells (fibroblasts), and (5) 2 isolated ECM components, laminin and type I collagen. From the first day in culture, retinal explants extended neurites when placed on Schwann cells without ECM. Outgrowth on Schwann cells expressing ECM was also extensive, but not obviously different form that on Schwann cells alone. Ultrastructural study revealed that $95 \%$ of retinal neurites in ECM-containing cultures contacted other neurites and Schwann cell surfaces exclusively. On cell-free ECM prepared from neuron-Schwann cell cultures, neurite extension was poor to nonexistent. No neurite outgrowth occurred on fibroblasts. Retinal explants also failed to extend neurites onto purified laminin and ammoniated type I collagen substrata; however, growth was rapid and extensive on air-dried type I collagen. In cultures contianing islands of air-dried type I collagen on a laminin-coated coverslip, retinal explants attached and extended neurites on collagen, but these neurites did not extend off the island onto the laminin substratum. We conclude from these experiments that neurite extension from embryonic rat retina is supported by a factor found on the surface of Schwann cells and that neither organized nor isolated ECM components provide this neurite promotion. These findings are discussed in relation to possible species differences in growth requirements for retinal ganglion cell neurites and to the specificity of response of different CNS neurites to ECM substrata.

\footnotetext{
Received Apr. 29, 1987; accepted Aug. 5, 1987.

We thank Dr. March Ard for many helpful suggestions, Dr. Mary Bunge for her help in interpreting our electron micrographs, Ann Williams and Peggy Bates for assistance with electron microscopy, Artree James and Laura Tynan for lab oratory assistance, Joe Hayes for photographic work, and Susan Mantia for exper secretarial assistance. This work is supported by NIH Grants NS09923 (to R.P.B.) and NS21771 (to M.I.J.). N.K. is supported by NIH Training Grant NS07071.

Correspondence should be addressed to Dr. Naomi Kleitman, Department of Anatomy and Neurobiology, Washington University School of Medicine, 660 South Euclid Avenue, St. Louis, MO 63110.

Copyright (c) 1988 Society for Neuroscience $0270-6474 / 88 / 020653-11 \$ 02.00 / 0$
}

Understanding the reasons why higher vertebrates have the capacity to regenerate peripheral but not central nerve fibers has been a perplexing problem in neurobiology. Recent studies have shown that components of the environment through which injured nerves grow influence the extent of regeneration. In a direct comparison, segments of sciatic nerve, but not of optic nerve, supported PNS neurite outgrowth, demonstrating the failure of the adult CNS milieu to support regeneration in nerves otherwise capable of regrowth (Bray et al., 1981; Schwab and Thoenen, 1985; Carbonetto et al., 1987). Conversely, the striking outgrowth of injured CNS axons into sciatic nerve autografts demonstrates that neurons of the adult mammalian CNS maintain the ability to regenerate if provided with a permissive environment (Richardson et al., 1980; So and Aguayo, 1985).

The specific components of the PNS environment that support or guide regenerating nerves have not been precisely defined, though surviving Schwann cells and/or the surrounding extracellular matrix (ECM) have long been thought to play essential roles in stimulating or guiding regrowth (for discussion, see Bunge, 1983). In the PNS, basal lamina tubes from which intrinsic muscle fibers or Schwann cells have been removed can support regeneration (Ide et al., 1983; Keynes et al., 1984). ECM components may be important in both regenerating and developing systems. Tissue culture studies have demonstrated that known ECM components, such as laminin, fibronectin, and collagens, support neurite outgrowth from embryonic neurons of both the PNS and CNS (Akers et al., 1981; Manthorpe et al., 1983; Rogers et al., 1983; Adler et al., 1985). Alternatively, glial cell surfaces themselves support neurite outgrowth in tissue culture (McCaffery et al., 1984; Noble et al., 1984; Fallon, 1985a, b).

The relative roles played by cellular and extracellular components of the environment in sustaining growth from CNS tissue are unknown, as is the extent to which requirements differ for each CNS neuronal type. Observations of specific portions of the CNS isolated in culture and exposed to known cell types or their products can yield important information about specific interactions, as in the studies cited above. However, direct comparisons of cellular and ECM influences on a single CNS system have rarely been undertaken. Also rare are studies of neurite growth on ECM organized by Schwann cells into a discrete basal lamina structure (Ard et al., 1987).

In the present report we compare neurite growth on Schwann cell surfaces with that on ECM organized by Schwann cells, using rat retinal tissue as a neurite source. Retinal neurite outgrowth has been previously studied in relation to isolated ECM 
components (Akers et al., 1981; Thompson and Pelto, 1982; Manthorpe et al., 1983; Rogers et al., 1983; Adler et al., 1985; Perris et al., 1986; Hall et al., 1987) or glial and neuronal cell surfaces (Bonhoeffer and Huf, 1980; McCafferty et al., 1984; Fallon, 1985b), but these conditions have not been compared directly. Furthermore, retinal neurite growth on complex ECM (including formed basal lamina tubes), such as that produced by Schwann cells interacting with axons, has not been explored. Such direct comparisons are particularly relevant to interpreting studies of retinal axon regeneration through peripheral nerve grafts (So and Aguayo, 1985).

\section{Materials and Methods}

All cultures were prepared from embryonic day 15 Sprague-Dawley rats (Chappel Breeders, St. Louis, MO), except fibroblast monolayers, which were prepared from day 21 embryos (the day after insemination is day $0)$.

Culture media. Media formulas used in these experiments have been described previously (Wood, 1976; Bunge et al., 1983). In brief, medium C10, consisting of Earle's Minimum Essential Medium (EMEM; Gibco, Grand Island, NY) supplemented with $10 \%$ human placental serum (HPS), $25 \mathrm{U} / \mathrm{ml} 7 \mathrm{~S} \mathrm{NGF}$, and $0.6 \%$ gluose, was used to prepare pure dorsal root ganglion (DRG) neuron and Schwann cell cultures. Fluorodeoxyuridine ( $\mathrm{FdU}$ ) and uridine (both at $10^{-5} \mathrm{M}$ ) were added on alternate feed periods to eliminate fibroblasts from the cultures. Undifferentiated DRG-Schwann cell cultures were maintained in N2-defined medium (Bottenstein and Sato, 1979; Bunge et al., 1982) supplemented with $50 \mathrm{U} / \mathrm{ml}$ NGF. Medium E-15, used to induce myelination and basal lamina formation (Eldridge et al., 1987), consisted of EMEM plus $15 \% \mathrm{HPS}, 25 \mathrm{U} / \mathrm{ml} \mathrm{NGF}$, and $50 \mu \mathrm{g} / \mathrm{ml}$ ascorbate. Fibroblast monolayers were prepared in E-FBS-15 feed, which was EMEM plus 15\% fetal bovine serum and $0.2 \%$ glucose. Finally, retinal explants in all substratum conditions were fed $\mathrm{C} 10-2$ medium ( $\mathrm{C} 10$ plus $2 \%$ chick embryo extract; Roufa et al., 1983).

Culture substrata. Cultures were prepared in $25 \mathrm{~mm}$ Aclar fluorocarbon dishes or on $22 \mathrm{~mm}$ acid-cleaned glass coverslips, as described previously (Masurovsky and Bunge, 1968; Wood, 1976; Johnson and Argiro, 1983). Collagen substrata were prepared from acetic acid-extracted rat tail collagen either by air-drying at room temperature (ADC) or by a 2 min exposure to ammonia vapors, rinsing with water, and air-drying (ammoniated collagen) (Wood, 1976; Johnson and Argiro, 1983). Laminin (Collaborative Research; $5 \mu \mathrm{g}$ in $30 \mu \mathrm{l}$ of $0.05 \mathrm{~m}$ carbonate buffer, $\mathrm{pH} \mathrm{9.6)}$ was applied to $22 \mathrm{~mm}$ glass coverslips at $35^{\circ} \mathrm{C}$ overnight. In some cases, laminin coverslips were pretreated with polyornithine $(1 \mathrm{mg} / \mathrm{ml}$ in $0.15 \mathrm{~m}$ borate buffer for $30 \mathrm{~min}$ at room temperature). We also tested neurite behavior at a border between collagen and laminin substrate. Small (approximately 3-mm-diameter) collagen drops were air-dried on glass coverslips, and then the entire coverslip was coated with polyornithine and laminin as described above.

The preparation of Schwann cells without ECM (SC without ECM) and Schwann cells with a formed basal lamina (SC with ECM) is complex, and is undertaken as follows: Because Schwann cells organize a complete basal lamina only when in contact with axons (and in fully supplemented medium), it is necessary to first establish sensory neuronSchwann cell cultures and allow these to mature to provide the cellular/ ECM components for these experiments. SC without ECM are prepared similarly, but are grown in an unsupplemented medium that does not allow basal lamina deposition by Schwann cells.

Schwann cell beds were prepared from DRG cultures on ammoniated collagen (Bunge et al., 1983). Briefly, DRGs were plated as explants or after trypsin dissociation, treated for 2 weeks with $\mathrm{C} 10$ and FdU to remove fibroblasts (Cornbrooks et al., 1983), and reseeded with purified DRG Schwann cells. Cultures were maintained on N2 for 3 weeks to allow full Schwann cell repopulation. Some cultures were then switched to E-15 medium to induce myelination and basal lamina formation (Moya et al., 1980; Eldridge et al., 1986); others were retained on N2 to provide Schwann cells that were unable to organize ECM. Then, 2$3 \mathrm{~d}$ before placement of retinal explants, DRG neurons were removed from the central regions of all cultures, both those providing SC with ECM and those providing SC without ECM. Some SC with ECM cultures were extracted to remove cellular constituents by the method described by Meezan et al. (1975; see also Carey et al., 1983), using 3\%
Triton $\mathrm{X}-100\left(4^{\circ} \mathrm{C}, 30 \mathrm{~min}\right), 0.1 \mathrm{mg} / \mathrm{ml}$ DNAase $\mathrm{I}$ in $1 \mathrm{M} \mathrm{NaCl}$ with 1 $\mathrm{mg} / \mathrm{ml} \mathrm{BSA} \mathrm{(room} \mathrm{temperature,} 30 \mathrm{~min}$ ), and $4 \%$ deoxycholate $\left(4^{\circ} \mathrm{C}\right.$, $30 \mathrm{~min}$ ), followed by water rinses. In another set of cultures, cellular elements were destroyed and removed by two 10 min periods of freezing $\left(-80^{\circ} \mathrm{C}\right)$ and thawing, followed by extensive water rinses. In a final set, cultures were simply disrupted osmotically by repeated water rinses. These treatments thus provided substrata with ECM but without viable cellular elements.

Beds of embryonic day 21 rat fibroblasts were prepared from fragments of internal cranial periosteum explanted onto ammoniated collagen in E-FBS-15 medium. $\Lambda$ fter 2 weeks in culture, $2 \mathrm{~mm}^{2}$ areas of the fibroblast monolayer were transplanted to fresh collagen and maintained for 3 weeks in E-FBS-15 until retinal explants were plated.

Retinal explants. Pregnant rats were anesthetized with ether on gestational day 15 and embryos were removed. Whole eyes were kept in Leibovitz's L-1 5 medium during the dissection. The retina was dissected free of sclera and lens tissue, then bisected or trisected through the optic disk. Retinal explants were placed on prepared substrata in C10-2 medium. Cultures were incubated at $35^{\circ} \mathrm{C}$ in a $\mathrm{CO}_{2}$-buffered humidified atmosphere. Neurite outgrowth was observed daily in living cultures on a Zeiss inverted microscope with phase-contrast optics.

Immunofluorescence. To visualize the extent of ECM deposition, selected cultures were washed in L-15 plus $10 \%$ heat-inactivated horse serum, incubated with primary antibodies to laminin (Bethesda Rescarch Lab) or fibronectin (the gift of Dr. John MacDonald) for $30 \mathrm{~min}$ at room temperature, rinsed, and incubated with a fluorescein-conjugated goat anti-rabbit IgG secondary. To visualize the extent of neurite outgrowth, cultures were then (1) fixed in $4 \%$ paraformaldehyde in 0.1 $M$ phosphate buffer (10 min, room temperature), (2) permeabilized with $95 \%$ ethanol, $5 \%$ acetic acid $\left(-20^{\circ} \mathrm{C}, 10 \mathrm{~min}\right)$, (3) rinsed and incubated with mouse monoclonal anti-neurofilament antibody (RT97 ascites, 1:100; Wood and Anderton, 1981) for $30 \mathrm{~min}$ at room temperature, followed by a rhodamine-conjugated goat anti-mouse secondary (Cappel; $30 \mathrm{~min}$ at room temperature). Control cultures were stained as above, except that the primary antibody was omitted. Cultures were mounted and observed on a Zeiss Universal microscope equipped for epifluorescence.

For detailed light-microscopic examination, a series of cultures was also stained with Sudan black, as described by Wood (1976). Cultures were fixed overnight with $2 \%$ glutaraldehyde in $0.05 \mathrm{M}$ phosphate buffer with $0.1 \mathrm{M}$ sucrose, then stained in $1 \% \mathrm{OsO}_{4}$ in phosphate buffer for 1 $\mathrm{hr}$, rinsed, dehydrated, and stained in $0.5 \%$ Sudan black in $70 \%$ ethanol. After gradual rehydration, cultures were washed in phosphate buffer and mounted on slides.

Electron microscopy. Selected cultures were fixed overnight in $2 \%$ glutaraldehyde in $0.1 \mathrm{M}$ phosphate buffer with $80 \mathrm{mM}$ sucrose, then rinsed, postfixed in $2 \% \mathrm{OsO}_{4}$ in $0.1 \mathrm{M}$ phosphate buffer, dehydrated in ethanol, and embedded in Polybed (Polysciences). Thin sections were stained with lead citrate and uranyl acetate and viewed in a Philips 300 transmission electron microscope.

\section{Results}

\section{Collagen substrata}

As has been described previously (Bray et al., 1980), E-15 retinal explants attached to and rapidly extended neurites on ADC with a remarkable consistency (102 of 111 explants; see Table 1). Neurites extended radially from the explants, originating initially and maximally from the optic disk region. Outgrowth also commonly appeared from other areas of the explant. Individual neurites or small fascicles of neurites (Fig. 1 $a$ ) extended along the collagen substratum as a coherent front at an initial rate of up to $1 \mathrm{~mm} / \mathrm{d}$. Neurites were accompanied by the migration of a small number of non-neural cells, which we believe to be macrophages (Fig. 1b) on the basis of their morphology in culture, their failure to express laminin immunoreactivity, and their ultrastructural characteristics. These cells appeared to migrate independent of retinal neurites. Neurite extension continued for up to 6 or $7 \mathrm{~d}$ under these culture conditions, to a final length of up to $5 \mathrm{~mm}$, after which time atrophy of the retinal ganglion cells occurs (P. Wood and A. K. Williams, unpublished 

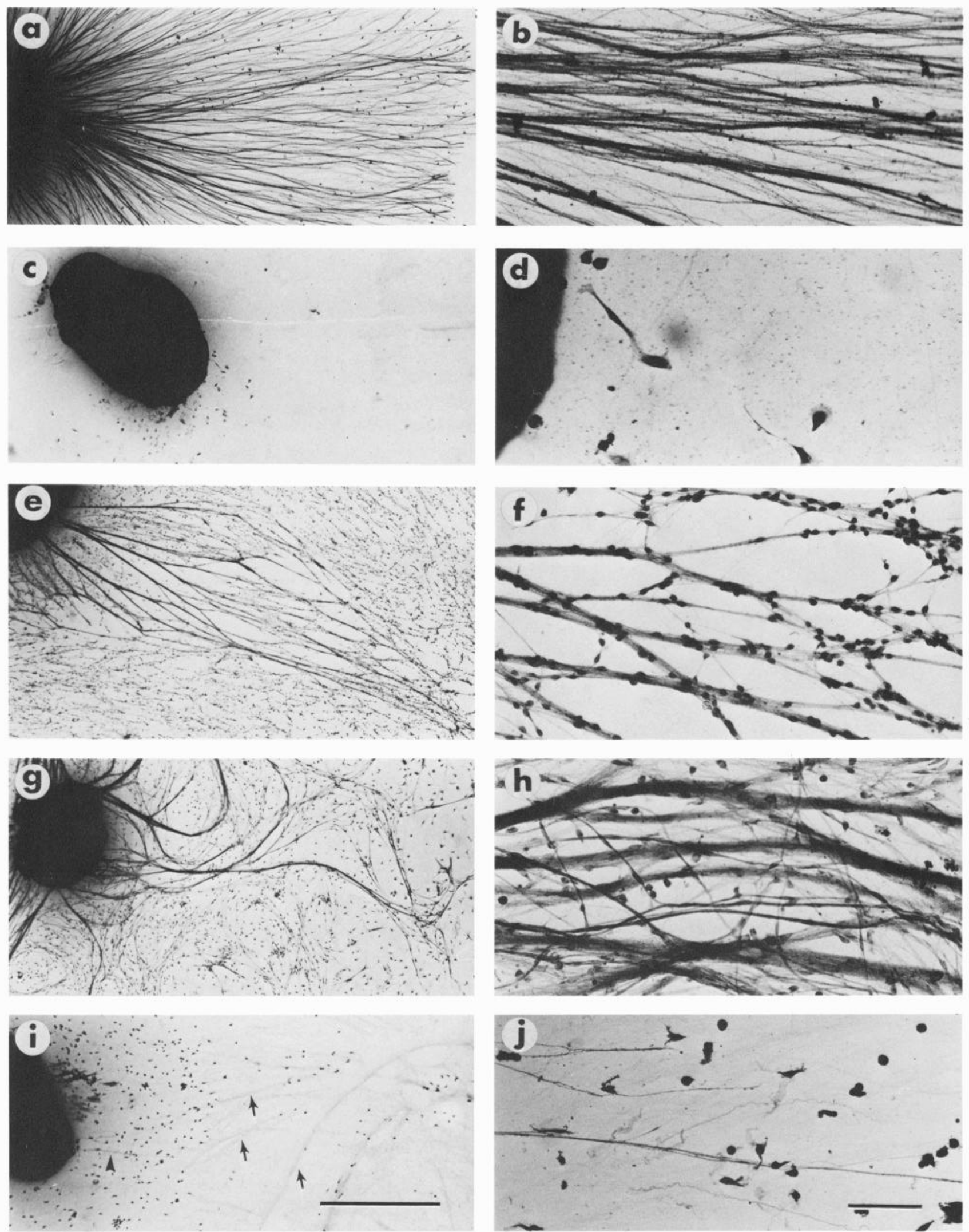

Figure 1. Outgrowth from E-15 retinal explants on air-dried type I collagen (ADC; $a, b)$, ammoniated collagen $(c, d)$, SC without ECM $(e, f)$, SC with $\operatorname{ECM}(g, h)$, and detergent-extracted $\operatorname{ECM}(i, j)$. ADC and SC with or without ECM support extensive neurite growth, while ECM alone and ammoniated collagen (which also underlies all SC and ECM cultures) do not. $g$, Retinal neurites follow the irregular cordons of SC and basal lamina laid down by sensory neurites. Debris along such tracts are visible in extracted ECM culture (i, arrows). The entire retinal neurite outgrowth, 3 small fascicles, extend along these tracts $(i$, arrowhead, and $j)$. Non-neuronal cells present on collagen and extracted ECM $(a-d, i, j)$ have migrated from the retinal explants. Fixed 5-6 d after plating retinal explants; Sudan black stain. Bar in $i, 1 \mathrm{~mm}(a, c, e, g, i) . \operatorname{Bar}$ in $j, 100 \mu \mathrm{m}(b, d, f, h, j)$. 
Table 1. Neurite outgrowth from retinal explants

\begin{tabular}{|c|c|c|c|}
\hline \multirow[b]{2}{*}{ Substratum } & \multicolumn{2}{|c|}{ Estimate of growth ${ }^{a}$} & \multirow{2}{*}{$\begin{array}{l}\text { No. with } \\
\text { neurites/no. } \\
\text { tested }\end{array}$} \\
\hline & Density & $\begin{array}{l}\text { Neurite length } \\
\text { in } \mathrm{mm}^{b}(\mathrm{n})\end{array}$ & \\
\hline Air-dried collagen & +++++ & $3.4 \pm 0.1(18)$ & $102 / 111$ \\
\hline Ammoniated collagen & 0 & 0 & $0 / 64$ \\
\hline Schwann cells only & +++ & $3.4 \pm 0.4(5)$ & $27 / 33$ \\
\hline Schwann cells with ECM & +++ & $2.9 \pm 0.2(4)$ & $12 / 12$ \\
\hline \multicolumn{4}{|l|}{ Extracted ECM } \\
\hline Water & + & $1.0 \pm 0.3(6)$ & $14 / 16$ \\
\hline Detergents & $0 /+$ & $0.5 \pm 0.4(2)$ & $6 / 58$ \\
\hline Freeze/water & $0 /+$ & $0.6 \pm 0.2(2)$ & $3 / 6$ \\
\hline Laminin & 0 & 0 & $3 / 62$ \\
\hline Fibroblasts only & 0 & 0 & $0 / 12$ \\
\hline
\end{tabular}

${ }^{a}$ From cultures fixed after 5-6 d in vitro, osmicated, and stained with Sudan black

${ }^{b}$ Mean \pm SEM of maximum neurite length from each explant.

observations); by $14 \mathrm{~d}$ in vitro, most of the neuritic outgrowth had disintegrated. Thus, all present observations pertain to the promotion of initial neurite growth and not to long-term trophic maintenance.

Retinal explants never extended neurites onto ammoniated
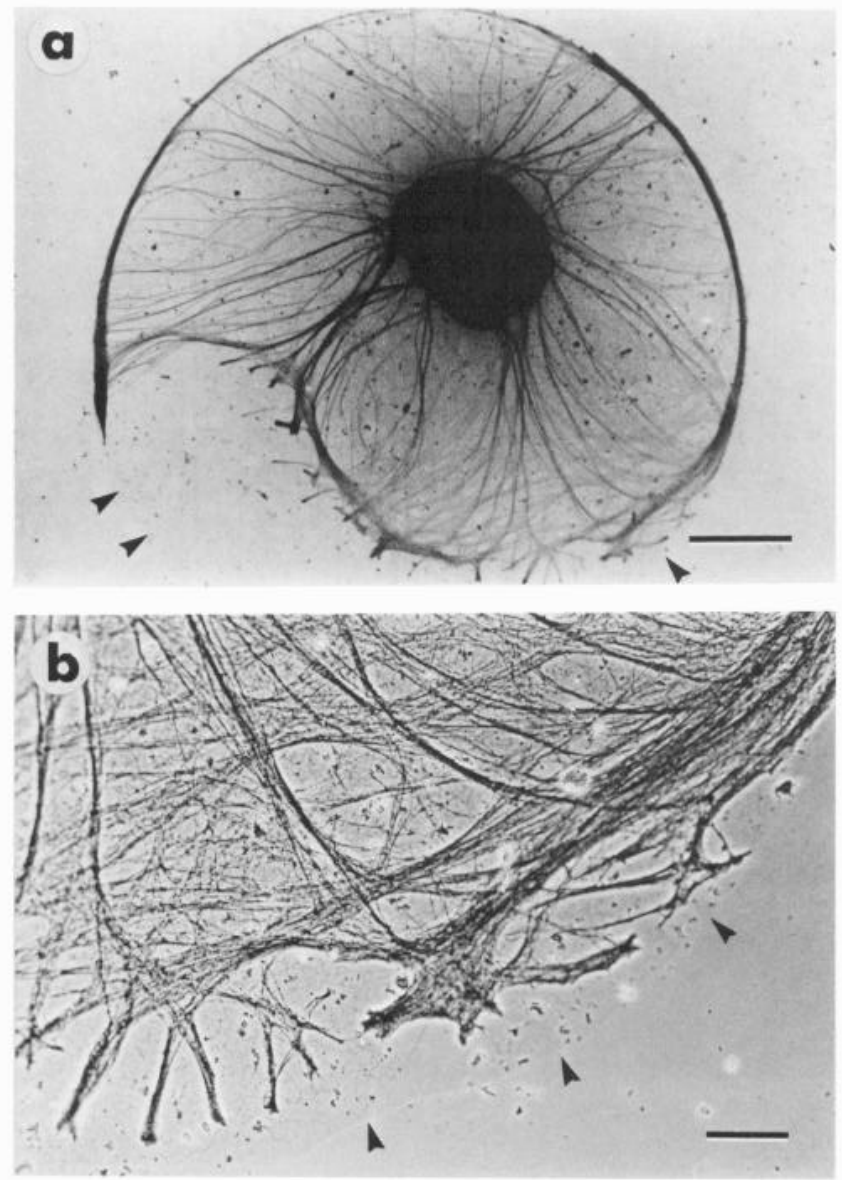

Figure 2. a, Retinal explant plated onto an air-dried collagen drop within a laminin-coated coverslip. Retinal neurites grow to the edge of the collagen but not onto the surrounding laminin-coated areas (arrowheads, substratum border in the lower part of the figure). Bar, $500 \mu \mathrm{m}$. $b$, Detail of neurite fasciculation at the collagen/laminin border (arrowheads, border). Bar, $100 \mu \mathrm{m}$. Fixed, $5 \mathrm{~d}$ in culture, Sudan black stain. collagen, although explants remained attached to this substratum for at least a week, and a small non-neural cell migration from the explants was noted (Fig. 1, $c, d$ ). Because ammoniated collagen was the substratum underlying the Schwann cell and fibroblast cultures, neurite outgrowth in the latter cultures was considered to be due to neurite interaction with these cells or to conditioning of the meidum or collagen by these cells, e.g., by the deposition of ECM components.

\section{Laminin}

A purified laminin substratum did not support secure attachment of retinal explants or neurite outgrowth. Explants attached to laminin-coated coverslips (with or without polyornithine pretreatment) and only 3 out of 62 tested extended a few short neurites after $24 \mathrm{hr}$ in culture. Even these few neurites retracted and, after 4-5 d, the explants detached from the substratum.

When explants were placed on a drop of air-dried collagen within a laminin-coated coverslip, neurites extended normally along the collagen-coated region (Fig. 2). Neurites did not extend off the edge of the collagen drop onto the laminin substratum, but turned, fasciculated, and encircled the collagen/laminin border (Fig. $2 b$ ). Explants placed on the border extended neurites only to the collagen-coated side, and explants placed off the drop, on the laminin, did not extend neurites at all.

\section{Live cells}

In cultures of Schwann cells lacking an organized ECM (SC without ECM) examined $3 \mathrm{~d}$ after removal of DRG neuronal cell bodies, the Schwann cells retained a bipolar morphology, with little apparent migration away from sites of degenerated DRG neurite pathways. At the time of fixation ( $8 \mathrm{~d}$ after explant removal and $5 \mathrm{~d}$ after retinal explant addition), those Schwann cells not contacting retinal neurites formed a homogenous but diffuse population. Many gaps between cells revealed the underlying ammoniated collagen layer. Retinal explants readily attached to the Schwann cell beds and extended neurites within the first day in culture. Initially, it was impossible to reliably discern the extent of outgrowth of fine retinal fascicles among the Schwann cell population in living cultures. Gradually, Schwann cells in areas of neurite outgrowth migrated to positions along thickening fascicles of retinal neurites (Fig. 1, $e, f$ ). The thickness of the retinal fascicles increased with time in culture, because of either late ingrowth of retinal neurites along 

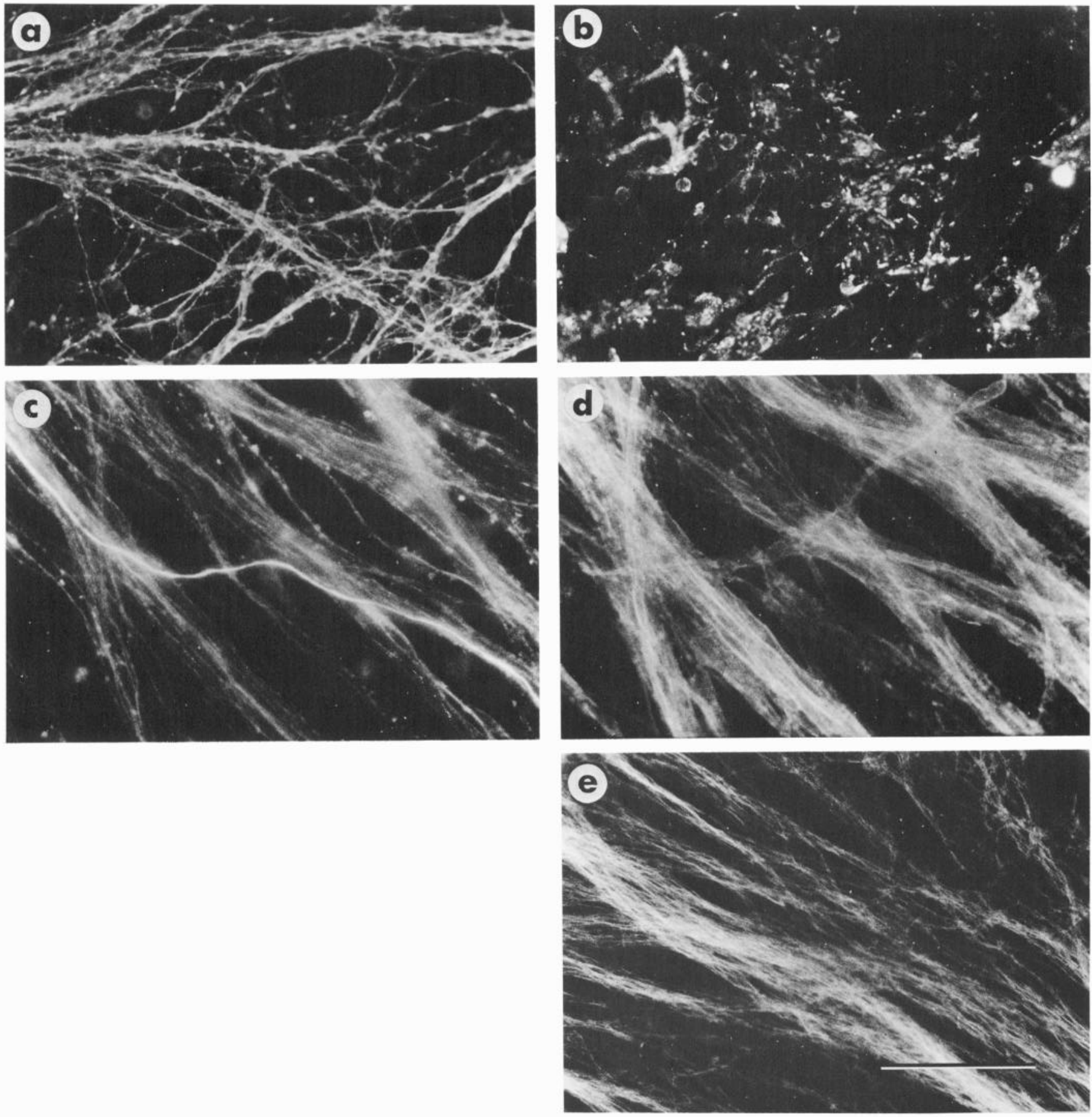

Figure 3. Immunofluorescent staining with antibodies to neurofilaments $(a, c)$ or laminin $(b, d, e) . a$, Retinal neurites extend across a field of SC without ECM. $b$, Punctate laminin staining is expressed by SC underlying neurites shown in $a$. $c$, Retinal neurites extend along tracts of SC with ECM. $d$, Continuous laminin staining of basal lamina in corresponding field of SC with ECM. $e$, Laminin staining in detergent-extracted ECM culture. No retinal neurites extended on this substratum. Bar, $100 \mu \mathrm{m}$.

the original fascicles or secondary fasciculation by adhesion of neurites to aggregating Schwann cells. By fixation at 5-6 d after retina addition, neurite lengths had reached 3-4 $\mathrm{mm}$ (Table 1; Fig. 1e). These SC without ECM expressed punctate surface immunostaining for laminin (Fig. $3 b$ ). Electron microscopy revealed that, within a given section, the majority of retinal neurites contacted only other neurites. Schwann cells and their processes were interspersed through the fascicles, in direct association with, but not ensheathing, the retinal neurites (Fig. $4 a$ ). In these cultures, no basal lamina was observed along Schwann cell surfaces (Fig. $4 a$, inset). In one group of explants kept for 2 weeks in culture on Schwann cell beds, neurite disintegration was pronounced during the second week. Thus, whereas contact with Schwann cells provided effective support for neurite growth, this contact did not appear to promote the long-term survival of retinal ganglion cells in vitro.

After sensory neurons were removed from cultures with Schwann cells that have organized ECM(SC with ECM), Schwann 

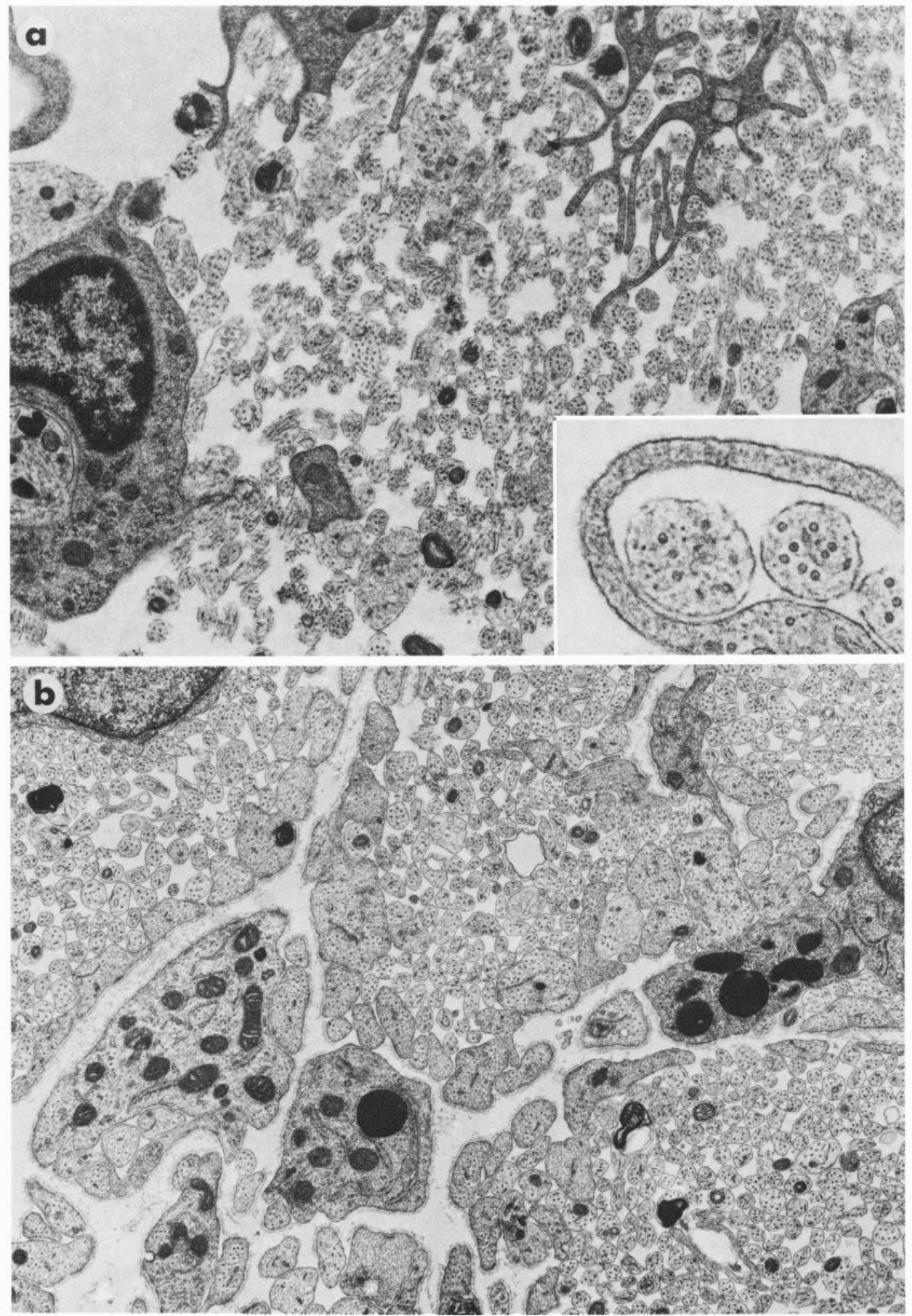

Figure 4. Electron micrograph of retinal neurite fascicles in SC culture without $(a)$ and with $(b)$ ECM. $a$, Retinal neurites fasciculate loosely, in contact with the processes and somata of SCs not expressing a basal lamina. Inset, close association of retinal neurites to a SC process in the complete absence of a basal lamina on the SC surface. $b$, SCs expressing a basal lamina surround fascicles of retinal neurites. Neurites are separated from the basal lamina by a single layer of SC processes. Fixed $5 \mathrm{~d}$ after plating retinal explants. $a, b, \times 17,600 ;$ inset, $\times 70,300$ 


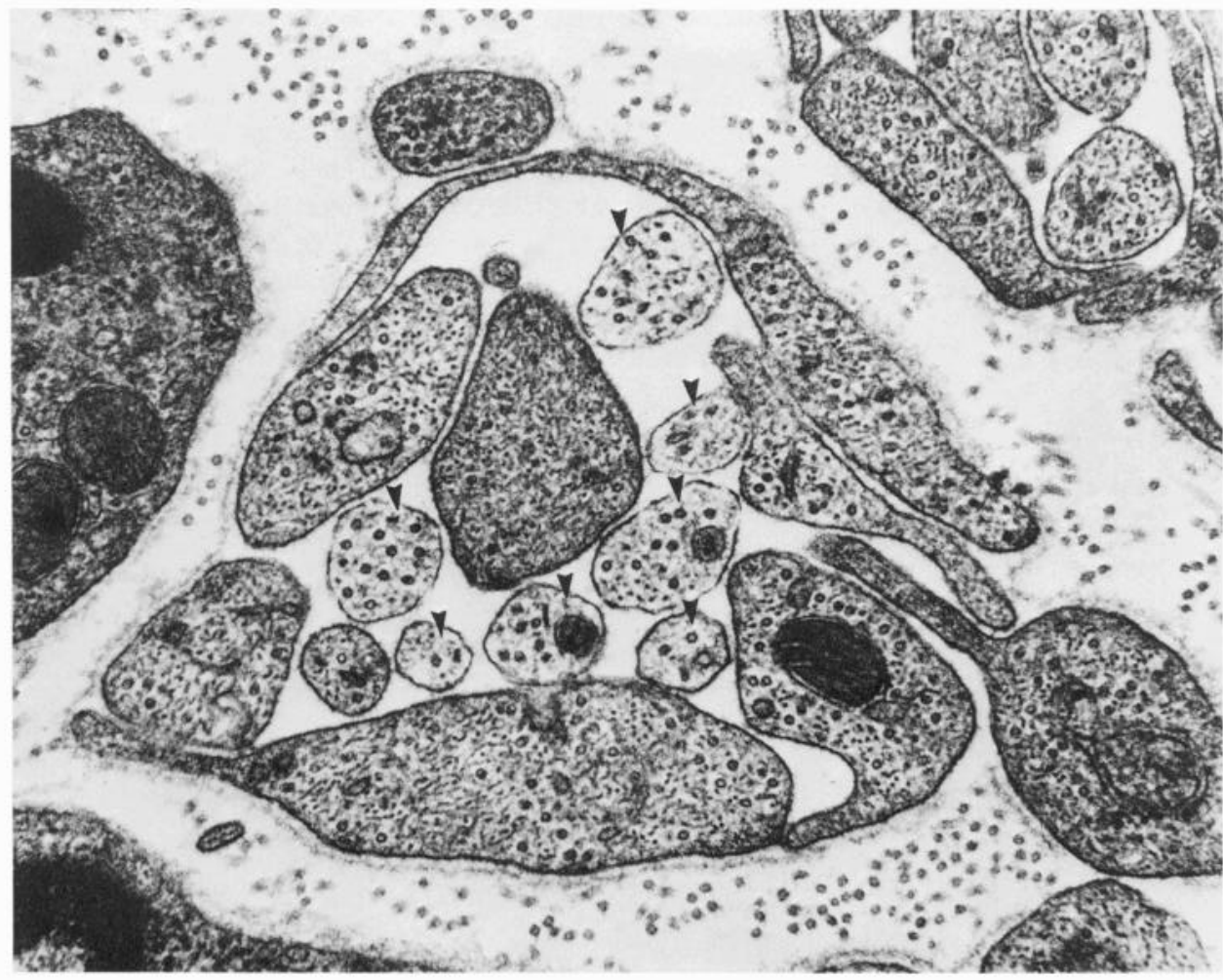

Figure 5. Small fascicle of retinal neurites in SC with ECM culture. Seven neurites (arrowheads) are surrounded by Schwann cell processes, and the entire fascicle is enclosed in a continuous basal lamina. Criteria for identification of neurites and analysis of contact in fascicles such as this are discussed in the text. Fixed $5 \mathrm{~d}$ after plating of retinal explants. $\times 50,600$. cells retained their positions along degenerated DRG fascicles. Again, retinal explants attached to these Schwann cell beds and extended neurites along pre-existing Schwann cell-basal lamina tracts. In unfixed cultures, neurite extent was impossible to detect reliably. In fixed and stained cultures, however, the extent of outgrowth proved to be extensive (Fig. $1 \mathrm{~g}$ ), but restricted almost entirely to pre-existing Schwann cell tracts (Figs. 1g, 3c). These cultures stained extensively for laminin in continuous linear profiles along Schwann cell tracts (Fig. 3d). In several cultures, large fascicles of hundreds of retinal neurites formed. Electron-microscopic analysis showed that these were surrounded by a layer of Schwann cell processes, which were, in turn, surrounded by a basal lamina (Fig. $4 b$ ). In other culture areas, neurites formed small fascicles or associated individually with Schwann cell processes (Fig. 5). To determine whether neurites were associated with Schwann cell surfaces, basal lamina, or both, we analyzed a sample of small fascicles. Neurites were distinguishable from Schwann cell processes by several criteria: Schwann cell cytoplasm was more electron-dense than that of neurites, and often contained large arrays of filaments. Neurites did not have bundles of filaments; however, their microtubules were characterized by filamentous sidearms. Finally, fixation of retinal neurite membranes was often less than optimal, further distinguishing neurites from the better-preserved Schwann cell processes.

Our quantitative analysis revealed that of 545 processes observed along basal lamina, fewer than $1 \%$ were identifiable as neurites. Conversely, of the 104 neurites identified in this sample, all but 5 were separated entirely from the basal lamina by intervening Schwannn cell processes. No neurites were seen without some association to other neurite or Schwann cell processes.

Although quantification of the length or density of neurites in the thick, curvilinear fascicles was not attempted, the overall extent of outgrowth in cultures of SC with ECM was not obviously enhanced over that observed in cultures of SC without ECM.

Retinal explants did not extend neurites on periosteal fibroblast monolayers, although the explants remained attached and macrophages migrated out along the monolayer (Fig. 6). These fibroblasts expressed immunostaining for fibronectin and, to a lesser extent, for laminin (Fig. 6, $b, c$ ).

\section{Cell-free ECM substrata}

Our goal was to remove Schwann cell components with minimal loss of ECM components in order to evaluate the ability of retinal explants to extend neurites on Schwann cell ECM only. We used 3 techniques of increasing severity to remove Schwann cell body components: osmotic shock, freezing, and chemical extraction. The chemical-extraction procedure removes plasma membrane and integral membrane proteins, as well as nuclear and cytoplasmic cellular contents, while preserving ECM components (Carey et al., 1983; Eldridge et al., 1986). Osmotic and freezing techniques did not remove cellular elements as thoroughly as did chemical extraction (as judged by visible debris in Sudan black-stained cultures), but we compared these procedures to discern whether chemical treatments might have denatured ECM components. After even the most extreme of these treatments, remnants of the Schwann cell tracts were immunoreactive to basal lamina components such as laminin (Fig. $3 e$ ), as well as to heparan sulfate proteoglycan (Eldridge et al., 1986) and collagen type IV (Carey et al., 1983). After extraction, immunostaining was linear and continuous along areas where myelinated DRG fascicles had grown. As judged by the intensity of staining for laminin and heparan sulfate proteoglycan, these 

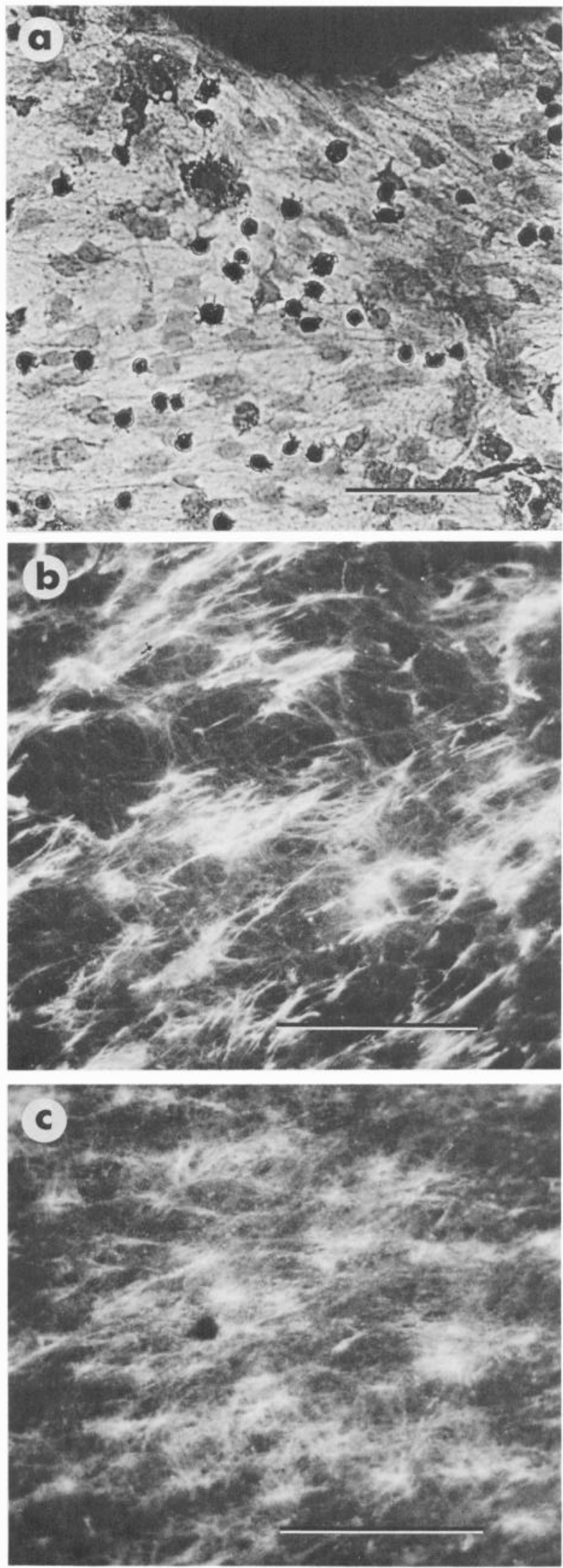

Figure 6. Retinal explants did not extend neurites on periosteal fibroblasts. $a$, Phase-contrast micrograph of fibroblast monolayer adjacent to retinal explant (top). Dark round cells are macrophages that have migrated from the explant. Sudan black stain, $5 \mathrm{~d}$ after plating retina. $b, c$, Immunofluorescent staining of fibroblast monolayer with antibodies to fibronectin $(b)$ and to laminin (c). Bars, $100 \mu \mathrm{m}$. components were present, but their amounts were diminished (C. F. Eldridge, unpublished observations).

Seventy-five percent of the retinal explants failed to extend neurites at all on ECM substrata. The remainder extended at best a few short $(<1 \mathrm{~mm})$ neurites on these substrata (Fig. $1, i$, $j$ ). Those neurites that did grow extended parallel to the underlying ECM tracts. A large population of macrophages migrated out from the explants, and by 5-6 d had removed substantial cellular debris from the substratum, but these areas continued to stain for laminin. Reduced neurite extension was observed for all 3 types of extractions, but to different degrees. On the basis of the percentage of explants displaying neuritic growth, and the number and length of those neurites (Table 1), it was found that outgrowth was greatest on osmotically extracted, and virtually nonexistent on frozen and chemically extracted, matrices. Although in all preparations strong immunostaining for basal lamina components was retained, we cannot determine whether the quantitative differences in neurite outgrowth was due to more complete removal of Schwann cell body components or to increased ECM degradation after the more severe treatments. Because visible cellular debris is retained among the ECM components after osmotic extraction, but not after detergent treatment, we favor the former interpretation.

\section{Discussion}

Schwann cell surfaces support extensive neurite outgrowth from explants of embryonic rat retina, while complex ECM remaining after the extraction of Schwann cells does not. Our demonstration of retinal neurite outgrowth on Schwann cell cultures supports previous observations (Noble et al., 1984; Fallon, 1985a) and extends them by comparing this outgrowth to that on fully differentiated Schwann cells that have organized ECM. Neurite extension on Schwann cells expressing ECM was not substantially enhanced over that on Schwann cell surfaces alone. In both types of culture, retinal neurites formed fascicles, contacting other neurites and Schwann cell processes; in neither did Schwann cells ensheathe individual retinal neurites. In cultures of SC with ECM, neurites were separated from the basal lamina by Schwann cell processes. Little to no neurite outgrowth was seen on cell-free ECM extracted by various methods. We conclude that Schwann cell ECM does not support or promote neurite outgrowth from embryonic rat retina.

The detergent-extracted ECM preparation used in these experiments has been shown to contain laminin, heparan sulfate proteoglycan (Eldridge et al., 1986), and type IV collagen (Carey et al., 1983). In general, isolated heparan sulfate proteoglycan does not promote neurite outgrowth (Manthorpe et al., 1983; Adler et al., 1985) and type IV collagen provides relatively poor support for outgrowth (Adler et al., 1985; Davis et al., 1985). Preparations of collagen exposed to ammonia vapors produce a flat substratum (Iversen et al., 1981; Roufa et al., 1983) on which retinal explants do not extend neurites. In our system, air-dried type I collagen was the only noncellular substratum to support retinal neurite outgrowth (as originally demonstrated by Bray et al., 1980). The growth-promoting properties of airdried collagen may be related to the 3-dimensionality of the substratum, which can profoundly alter cell motility and the morphology of neural and non-neural cells (Tomasek et al., 1982; Roufa et al., 1983; Coates, 1986; Kleitman and Johnson, 1986). The mechanisms by which growing processes interact with a 3-dimensional collagen substratum are as yet unknown.

There is substantial evidence that another ECM component, 
laminin, is a potent neurite-promoting agent for both peripheral and central nerves in vitro (Manthorpe et al., 1983; Rogers et al., 1983), which leads to the hypothesis that it may play a similar role in vivo. Recent studies show that laminin is present transiently in developing CNS, including the optic stalk, at a time when neurites extend to their target sites (Adler et al., 1985; McLoon et al., 1986; Rogers et al., 1986). In the present experiments, SC without ECM expressed punctate laminin-like immunoreactivity similar to that described on cell surfaces in the developing CNS (Liesi, 1985; Rogers et al., 1986). Retinal neurite outgrowth has also been demonstrated on astrocyte surfaces (McCaffery et al., 1984; Fallon, 1985a), which can also express punctate laminin immunostaining in vitro (Liesi et al., 1983; M. D. Ard and R. P. Bunge, unpublished observations). The presence of laminin was not, in itself, sufficient to elicit neurite growth in our system, either in isolated preparations on the surface of periosteal fibroblasts, or in a complex ECM preparation, wherein the laminin configuration would be more like that found in the PNS, associated with heparan sulfate proteoglycan, type IV collagen, and other matrix components.

The lack of rat retinal neurite growth on laminin substrata was surprising in light of previous reports of retinal outgrowth on laminin (Manthorpe et al., 1983; Rogers et al., 1983; Adler et al., 1985; Hall et al., 1987) and the successful growth of other CNS tissues on this substratum in many laboratories, including our own (Manthorpe et al., 1983; Rogers et al., 1983; Kleitman and Johnson, 1986; Ard et al., 1987; Bunge et al., 1987). In the present experiments, retinal explants attached to the laminin substratum, but neurites were not extended. Furthermore, once growing on small islands of collagen within a laminin-coated dish, retinal neurites avoided the surrounding laminin substratum, turning and continuing along the edge of the collagen. The explanation for this discrepancy in results may be a species difference in responsiveness of retinal tissue to the laminin substratum. Most previous studies of retina on laminin have examined embryonic chick tissue (Manthorpe et al., 1983; Rogers et al., 1983; Adler et al., 1985). A recent trial in our laboratory comparing chick (embryonic day 6) to E-15 rat tissue confirmed that chick explants were responsive to our air-dried collagen and laminin substrata (N. Kleitman, unpublished observations), while rat explants grew only on air-dried collagen. Smalheiser et al. (1984) reported that laminin concentrations 10-100 times that used in the present experiments reliably elicited growth from embryonic mouse retinal explants. This level far exceeds that used in most other preparations, including tests of chick retina and other mammalian CNS tissues and, presumably, that found in Schwann cell-derived ECM preparations. While the response of mammalian retina to extraordinarily high concentrations of laminin may indicate the presence of a small population of laminin receptors on these neurites, the present results indicate that any such receptors operate separately from, or are greatly facilitated by, responses to other glial cell surface ligands. Again, we would emphasize that these experiments do not disprove that laminin influences mammalian retinal neurite outgrowth in some way; however, neither do they support a role for laminin as a neurite-promoting factor in this system.

Alternatively, rat retinal ganglion cells may require a specific neurotrophic factor to survive under some culture conditions. Release by Schwann cells of laminin or other potentially neurotrophic or neurite-promoting substances into the culture medium was not tested in the present experiments; in previous studies, astrocyte-conditioned medium did not enhance retinal ganglion cell survival or neurite extension (McCaffery et al., 1984; Fallon, 1985a). Johnson et al. (1986), however, showed that, in dissociated cultures, rat retinal ganglion cells plated onto laminin did not survive without the addition of a brain-derived neurotrophic factor. In the presence of this factor, retinal ganglion cells survived and extended neurites on laminin. In the present experiments, on the basis of the length of neurites observed (i.e., several millimeters), it seems likely that retinal ganglion cells are the source of observed neurite outgrowth. Although a neurotrophic factor was clearly not required for retinal explants plated on air-dried collagen or on living Schwann cells, the failure of outgrowth under other conditions might have been due to poorer survival of retinal ganglion cells. Similarly, fibronectin, as expressed on fibroblast surfaces, was not sufficient for eliciting retinal neurite outgrowth in the present experiments. Purified fibronectin has, however, been shown to support rat retinal neurite outgrowth under some culture conditions, depending on the presence of a brain-derived growth factor (Turner et al., 1983). Therefore, failure of fibroblasts to elicit growth in our system and others (Noble et al., 1984; Fallon, 1985a) may have also been due to the absence of specific media components.

The presence of a neurite-promoting factor on glial ccll surfaces separate from that present in ECM has recently been described (Tomaselli et al., 1986). Such factors may act alone or in conjunction with other moieties, such as laminin in the PNS (Tomaselli et al., 1986). Rat retinal growth on cell surfaces seems to be determined by a factor(s) specific to glial cell surfaces (both astrocytes and Schwann cells). There is no evidence in our system for another, ECM-recognition receptor that would support growth on isolated ECM or enhance growth on Schwann cells expressing ECM at their surfaces. Rather, neurite-promoting surface ligands on cells expressing a basal lamina appear to be polarized to the surface opposite the ECM. Because it is extremely difficult to positively identify growth cones among complex assemblages of Schwann cell processes, we do not know whether retinal growth cones are restricted to specific parts of the Schwann cell surface. Nevertheless, retinal neurites were preferentially associated with the Schwann cell surface not related to a basal lamina. This pattern of growth resembles that observed in vivo. In the developing chick, retinal axons grow along aligned glial channels, with growth cones in contact with glial endfeet expressing a basal lamina on their opposite surface (Krayanek and Goldberg, 1981; Silver and Rutishauser, 1984). A recent study of regenerating goldfish retinal axons (Easter and Malinoski, 1986) showed that, unlike developing pathways, regenerating axons were found exclusively along astrocyte surfaces opposite those expressing a basal lamina. The identity of such cell surface ligands and the mechanisms by which expression of a basal lamina may polarize their distribution in the cell membrane are, as yet, unknown, but known adhesion molecules are almost certain to play a role. The presence of neural cell adhesion molecules (N-CAM) on retinal ganglion cells (Rutishauser, 1984) and on the astrocytic endfeet along which these axons grow (Silver and Rutishauser, 1984), and the demonstration that inhibition of N-CAM-mediated interactions disrupts retinal axon guidance (Silver and Rutishauser, 1984), are highly suggestive of a role for this adhesion molecule in interactions between retinal axons and glial cells. Other cell surface molecules are also likely to be involved in these interactions, such as purpurin, which interacts with N-CAM to stimulate retinal cell-substratum adhesion (Schubert et al., 1986). Whilc thcsc adhesion mol- 
ecules have been shown to have neurotrophic properties as well (Schubert and LeCorbiere, 1985), their effect on neurite promotion per se is not known.

Although retinal tissue is a commonly studied model for CNS growth under varied culture conditions, the present results indicate that, at least in the rat, there are important differences between the growth requirements of this and other CNS tissues. These differences may be related to developmental shifts specific to particular neuronal systems and timed to synchronize neurite outgrowth to changes in appropriate cellular and extracellular substrata (Singer et al., 1979; Silver and Sapiro, 1981; Silver et al., 1982; Cohen et al., 1986). Care must be taken in interpreting the function of ECM components produced at developmentally relevant times. Despite the recent demonstration of laminin expression along the developing rat optic tract (McLoon et al., 1986), the present experiments suggest that laminin and other ECM components may not function as neurite outgrowth-promoting factors in this system, but that this function may be performed by other ligands on glial cell surfaces.

\section{References}

Adler, R., J. Jerdan, and A. T. Hewitt (1985) Responses of cultured neural retinal cells to substratum-bound laminin and other extracellular matrix molecules. Dev. Biol. 112: 100-114.

Akers, R. M., D. F. Mosher, and J. E. Lilien (1981) Promotion of retinal neurite outgrowth by substratum-bound fibronectin. Dev. Biol. 86: $179-188$.

Ard, M. D., and R. P. Bunge (1986) Tissue culture observations on the interactions of astrocytes, extracellular matrix, and neurites. Soc. Neurosci. Abstr. 12: 394

Ard, M. D., R. P. Bunge, and M. B. Bunge (1987) A comparison of the Schwann cell surface and Schwann cell extracellular matrix as promoters of neurite growth. J. Neurocytol. 16: 539-555.

Bonhoeffer, F., and J. Huf (1980) Recognition of cell types by axonal growth cones in vitro. Nature 288: 162-164.

Bottenstein, J. E., and G. H. Sato (1979) Growth of a rat neuroblastoma cell line in serum-free supplemented medium. Proc. Natl. Acad. Sci. USA 76: 514-517.

Bray, D., P. Wood, and R. P. Bunge (1980) Selective fasciculation of nerve fibres in culture. Exp. Cell Res. 130: 241-250.

Bray, G. M., M. Rasminsky, and A. J. Aguayo (1981) Interactions between axons and their sheath cells. Annu. Rev. Neurosci. 4: 127162 .

Bunge, M. B., R. P. Bunge, D. J. Carey, C. J. Cornbrooks, C. F. Eldridge, A. K. Williams, and P. M. Wood (1983) Axonal and nonaxonal influences on Schwann cell development. In Developing and Regenerating Vertebrate Nervous Systems, P. W. Coates, R. R. Markwald, and A. D. Kenny, eds., pp. 71-105, Liss, New York.

Bunge, R. P. (1983) Aspects of Schwann cell and fibroblast function relating to CNS regencration. In Spinal Cord Reconstruction, C. C. Kao, R. P. Bunge, and P. J. Reier, eds., pp. 261-270, Raven, New York.

Bunge, R. P., M. B. Bunge, D. J. Carey, C. J. Cornbrooks, D. Higgins, M. I. Johnson, L. Iacovitti, D. C. Kleinschmidt, F. Moya and P. Wood (1982) Functional expression in primary nerve tissue cultures maintained in defined medium. Cold Spring Harbor Conf. Cell Prolif. 9: 1017-1031.

Bunge, R. P., C. F. Eldridge, M. D. Ard, and N. Kleitman (1987) Schwann cell contact as a factor in neuronal trophic support and the promotion of neurite growth. In Neurobiology of Amino Acids, Peptides and Trophic Factors, J. Ferrendelli, R. Collins, and E. Johnson, eds., Martinus Nijhoff, Boston, MA (in press).

Carbonetto, S., D. Evans, and P. Cochard (1987) Nerve fiber growth in culture on tissue substrata from central and peripheral nervous systems. J. Neurosci. 7: 610-620.

Carey, D. J., C. F. Eldridge, C. J. Cornbrooks, R. Timpl, and R. P. Bunge (1983) Biosynthesis of type IV collagen by cultured rat Schwann cells. J. Cell Biol. 97: 473-479.

Coates, P. W. (1986) Quantitation and morphological characterization of rapid axon and dendritic growth from single cerebral hemispheric neurons in hydrated collagen lattice culture. Dev. Brain Res. 25:1120.

Cohen, J., J. F. Burne, J. Winter, and P. Bartlett (1986) Retinal ganglion cells lose response to laminin with maturation. Nature 322 . 465-467.

Cornbrooks, C. J., D. J. Carey, J. A. McDonald, R. Timpl, and R. P. Bunge (1983) In vivo and in vitro observations on laminin production by Schwann cells. Proc. Natl. Acad. Sci. USA 80: 3850-3854.

Davis, G. E., S. Varon, E. Engvall, and M. Manthorpe (1985) Substratum-binding neurite-promoting factors: Relationships to laminin. Trends Neurosci. 8: 528-532.

Easter, S. S., and C. Malinoski (1986) Regenerating optic axons of goldfish do not grow on the basal lamina. Soc. Neurosci. Abstr. 12: 1504.

Eldridge, C. F., J. R. Sanes, A. Y. Chiu, R. P. Bunge, and C. J. Cornbrooks (1986) Basal lamina-associated heparan sulfate proteoglycan in the rat PNS: Characterization and localization using monoclonal antibodies. J. Neurocytol. 15: 37-51.

Eldridge, C. F., M. B. Bunge, and R. P. Bunge (1987) Differentiation of axon-related Schwann cells in vitro. I. Ascorbic acid regulates basal lamina assembly and myelin formation. J. Cell Biol. 105: 1023-1034.

Fallon, J. R. (1985a) Preferential outgrowth of central nervous system neurites on astrocytes and Schwann cells as compared with nonglial cells in vitro. J. Cell Biol. 100: 198-207.

Fallon, J. R. (1985b) Neurite guidance by non-neuronal cells in culture: Preferential outgrowth of peripheral neurites on glia as compared to nonglial cell surfaces. J. Neurosci. 5: 3169-3177.

Hall, D. E., N. M. Neugebauer, and L. F. Reichardt (1987) Embryonic neuronal retinal cell response to extracellular matrix proteins: Developmental changes and effects of the cell substratum attachment antibody (CSAT). J. Cell Biol. 104: 623-634.

Ide, C., K. Tohyama, R. Yokota, T. Nitatori, and S. Onodera (1983) Schwann cell basal lamina and nerve regeneration. Brain Res. 288: 61-75.

Iversen, P. L., L. M. Partlow, L. J. Stensaas, and F. Moatamed (1981) Characterization of a variety of standard collagen substrates: Ultrastructure, uniformity, and capacity to bind and promote growth of neurons. In Vitro 17: 540-552.

Johnson, J. E., Y.-A. Barde, M. Schwab, and H. Thoenen (1986) Brainderived neurotrophic factor supports the survival of cultured rat retinal ganglion cells. J. Neurosci. 6: 3031-3038.

Johnson, M. I., and V. Argiro (1983) Techniques in the tissue culture of rat sympathetic neurons. Methods Enzymol. 103: 334-347.

Keynes, R. J., W. G. Hopkins, and H.-L.C. Huang (1984) Regeneration of mouse peripheral nerves in degenerating skeletal muscle: Guidance by residual muscle fibre basement membrane. Brain Res. 295: 275281 .

Kleitman, N., and M. I. Johnson (1986) Olfactory bulb neurite extension in culture is age and substrate dependent. Soc. Neurosci. Abstr. 12: 1112 .

Krayanek, S., and S. Goldberg (1981) Oriented extracellular channels and axonal guidance in the embryonic chick retina. Dev. Biol. 84: 41-50.

Liesi, P. (1985) Do neurons in the veretebrate CNS migrate on laminin? EMBO J. 4: 1163-1170.

Liesi, P., D. Dahl, and A. Vaheri (1983) Laminin is produced by early rat astrocytes in primary culture. J. Cell Biol. 96: 920-924.

Manthorpe, M., E. Engvall, E. Ruoslahti, F. M. Longo, G. E. Davis, and $S$. Varon (1983) Laminin promotes neuritic regeneration from cultured peripheral and central neurons. J. Cell Biol, 97: 1882-1890.

Masurovsky, E. B., and R. P. Bunge (1968) Fluoroplastic coverslips for long-term nerve tissue culture. Stain Technol. 43: 161-165.

McCaffery, C. A., T. R. Raju, and M. R. Bennett (1984) Effects of cultured astroglia on the survival of neonatal rat retinal ganglion cells in vitro. Dev. Biol. 104: 441-448.

McLoon, S. C., L. K. McLoon, S. L. Palm, and L. T. Furcht (1986) Laminin is transiently expressed in the developing rat optic nerve during the time retinal axons are growing. Soc. Neurosci. Abstr. 12: 1211.

Meczan, E., J. T. Hjelle, and K. Brendel (1975) A simple, versatile, nondisruptive method for isolation of morphologically and chemically pure basement membranes from several tissues. Life Sci. 17: $1721-1732$

Moya, F., M. B. Bunge, and R. P. Bunge (1980) Schwann cells proliferate but fail to differentiate in defined medium. Proc. Natl. Acad. Sci. USA 77: 6902-6906. 
Noble, M., J. Fok-Seang, and J. Cohen (1984) Glia are a unique substrate for the in vitro growth of central nervous system neurons. J. Neurosci. 4: 1892-1903.

Perris, R., N. G. Carri, and T. Ebendal (1986) Differential promotion of retinal neurite outgrowth by isolated extracellular matrix components. Soc. Neurosci. Abstr. 12: 1112.

Richardson, P. M., U. M. McGuinness, and A. J. Aguayo (1980) Axons from CNS neurons regenerate into PNS grafts. Nature 284: 264-265.

Rogers, S. L., P. C. Letourneau, S. L. Palm, J. McCarthy, and L. T. Furcht (1983) Neurite extension by peripheral and central nervous system neurons in response to substatum-bound fibronectin and laminin. Dev. Biol. 98: 212-220.

Rogers, S. L., K. J. Edson, P. C. Letourneau, and S. C. McLoon (1986) Distribution of laminin in the developing peripheral nervous system of the chick. Dev. Biol. 113: 429-435.

Roufa, D. G., M. I. Johnson, and M. B. Bunge (1983) Influence of ganglion age, non-neuronal cells and substratum on neurite outgrowth in culture. Dev. Biol. 99: 225-239.

Rutishauser, U. (1984) Developmental biology of a neural cell adhesion molecule. Nature 310: 549-554.

Schubert, D., and M. LaCorbiere (1985) Isolation of an adhesionmediating protein from chick neural retina adherons. J. Cell Biol. 101: 1071-1077.

Schubert, D., M. LaCorbiere, and F. Esch (1986) A chick neural retina adhesion and survival molecule is a retinol-binding protein. J. Cell Biol. 102: 2295-2301.

Schwab, M. E., and H. Thoenen (1985) Dissociated neurons regenerate into sciatic but not optic nerve explants in culture irrespective of neurotrophic factors. J. Neurosci. 5: 2415-2423.

Silver, J., and U. Rutishauser (1984) Guidance of optic axons in vivo by a preformed adhesive pathway on neuroepithelial endfeet. Dev. Biol. 106: 485-499.

Silver, J., and J. Sapiro (1981) Axonal guidance during development of the optic nerve: The role of pigmented epithelia and other extrinsic factors. J. Comp. Neurol. 202: 521-538.

Silver, J., S. E. Lorenz, D. Wahlstein, and J. Coughlin (1982) Axonal guidance during development of the great cerebral commissures: Descriptive and experimental studies, in vivo, on the role of preformed glial pathways. J. Comp. Neurol. 210: 10-29.

Singer, M., R. H. Nordlander, and M. Egar (1979) Axonal guidance during embryogenesis and regeneration in the spinal cord of the newt: The blueprint hypothesis of neuronal pathway patterning. J. Comp. Neurol. 185: 1-22.

Smalheiser, N. R., S. M. Crain, and L. M. Reid (1984) Laminin as a substrate for retinal axons in vitro. Dev. Brain Res. 12: 136-140.

So, K.-F., and A. J. Aguayo (1985) Lengthy regrowth of cut axons from ganglion cells after peripheral nerve transplantation into the retina of adult rats. Brain Res. 328: 349-354.

Thompson, J. M., and D. J. Pelto (1982) Attachment, survival and neurite extension of chick embryo retinal neurons on various culture substrates. Dev. Neurosci. 5: 447-457.

Tomasek, J. J., E. D. Hay, and K. Fujiwara (1982) Collagen modulates cell shape and cytoskeleton of embryonic corneal and fibroma fibroblasts: Distribution of actin, $\alpha$-actinin and myosin. Dev. Biol. 92: 107-122.

Tomaselli, K. J., L. F. Reichardt, and J. L. Bixby (1986) Distinct molecular interactions mediate neuronal process outgrowth on nonneuronal cell surfaces and extracellular matrices. J. Cell Biol. 103: 2659-2672.

Turner, J. E., Y.-A. Barde, M. E. Schwab, and H. Thoenen (1983) Extract from brain stimulates neurite outgrowth from fetal rat retinal explants. Dev. Brain Res. 6: 77-83.

Wood, J. N., and B. Anderton (1981) Monoclonal antibodies to mammalian neurofilaments. Biol. Sci. Rep. 1: 263-268.

Wood, P. M. (1976) Separation of functional Schwann cells and neurons from normal peripheral nerve tissue. Brain Res. 115: 361-375. 